Archive for

Organic Chemistry

Arkivoc 2019, vi, 116-127

\title{
Theoretical and experimental investigation of NMR, IR and UV-visible spectra of hydroxyl-substituted-4-chloromethylcoumarin derivatives
}

\begin{abstract}
Chutipapha Loarueng, ${ }^{a}$ Bundet Boekfa, ${ }^{\text {a Suwatchai Jarussophon, }}{ }^{\mathrm{b}}$ Pawinee Pongwan, ${ }^{\mathrm{b}}$ Narongpol Kaewchangwat, ${ }^{b}$ Khomson Suttisintong, $^{\mathrm{b}}$ and Nongpanga Jarussophon*a
\end{abstract}

${ }^{a}$ Department of Chemistry, Faculty of Liberal Arts and Science, Kasetsart University, Kamphaeng Saen Campus, Nakhon Pathom 73140, Thailand

${ }^{b}$ National Nanotechnology Center, National Science and Technology Development Agency, 130 Thailand Science Park, Paholyothin Road, Klong Luang, Pathumthani, 12120, Thailand

Email: faasngi@ku.ac.th

Received 05-22-2019

Accepted 08-25-2019

Published on line 09-22-2019

\section{Abstract}

UV-Visible, FTIR and NMR experimental and theoretical spectral results have been compared for five substituted-4-chloromethylcoumarin derivatives $(6-\mathrm{OH}, 7-\mathrm{OH}, 6,7-\mathrm{di}-\mathrm{OH}, 7,8$-di-OH and 5,7-di-OH-substituted4-chloromethylcoumarins). The theoretical investigation was conducted using density functional theory (DFT), namely the M06-2X functional form with $6-311+G(2 d f, 2 p)$ basis set. The ${ }^{13} \mathrm{C}-N M R$ and ${ }^{1} \mathrm{H}-\mathrm{NMR}$ chemical shifts, vibrational spectra and molecular orbitals of the excited states were calculated based on their optimized geometries. The calculated values were found to have close agreement with the experimental values. The theoretical data are useful and could be important in the proper selection of compounds as intermediates for different chemical applications and modifications.

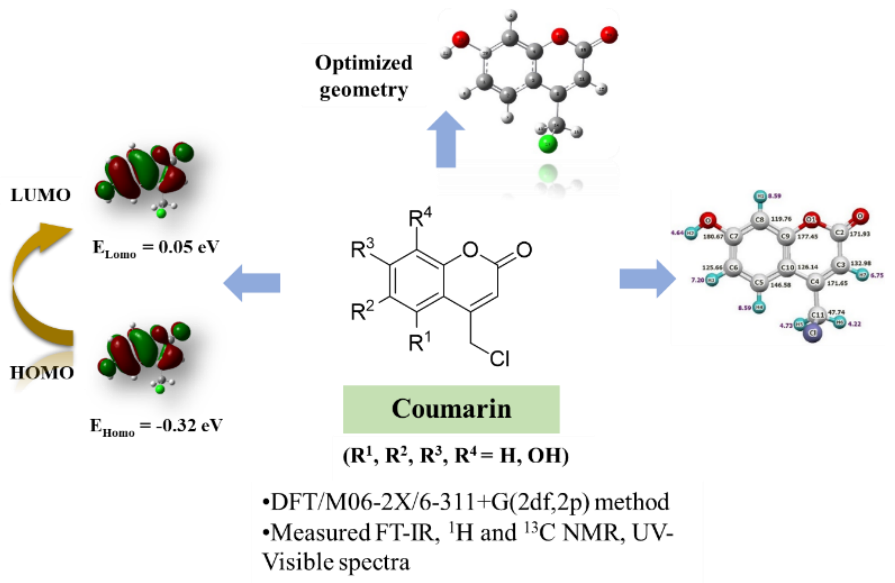

Keywords: Coumarins, UV-Visible, FTIR, NMR, MO theory, HOMO-LUMO, density functional theory, DFT 


\section{Introduction}

Coumarin derivatives are classified as part of the benzopyrone family, aromatic compounds which comprise bicyclic systems containing a benzene ring fused to an $\alpha$-pyrone ring. Coumarin derivatives are present in many naturally-occurring products, including tonka beans and sweet clover, and there has been a growing interest in their synthesis. ${ }^{1}$ Coumarin derivatives have been used widely as additives in the drug, food and cosmetic industries. From a medicinal perspective, their derivatives have exhibited various intriguing biological activities including anti-HIV, antimicrobial, anticancer, anti-inflammatory, anticoagulant, anticonvulsant, and antioxidant properties. ${ }^{2,3}$ The biological and pharmacological activities, and effective bioactivity in therapeutic applications of coumarin derivatives have been shown to be dependent upon the substitution patterns on the basic coumarin structure. ${ }^{4,5}$ Therefore, the substitution patterns may be used to modify the ring system for maximum pharmacological and therapeutic benefit.

Recently, the coumarin chromophore core structure has been used as a photo-labile protective group for carboxylates. ${ }^{6,7}$ This could present a significant investigational opportunity for controlling the release of several active ingredients in agrochemical applications. ${ }^{8-10}$ In addition, a long alkoxy hydrophobic side chain (C16) has been introduced to promote better adhesion of amphiphilic compounds applied on plant leaves. ${ }^{11}$

4-Chloromethylcoumarin derivatives act as good starting materials that could be simply enhanced to produce a large number of coumarin derivatives based on the desired physical properties needed. A number of studies of the spectroscopic and calculated-data results of this compound are intriguing.

The utilization of density functional theory (DFT) to calculate and optimize molecular structures of compounds, energies of chemical reactions, absorption energy and the scale value of harmonic vibrational frequencies has been widely used in comparisons with the outputs from experimental results. ${ }^{12-15}$ DFT calculations have been accepted by the quantum chemistry community based on the highly efficient predictions resulting from these computational approaches. Additionally, calculations of UV-Visible, FTIR and NMR spectroscopic properties were determined using DFT methodology. Good agreement was observed between the experimental and theoretical data. ${ }^{16} \mathrm{Al}$-Bayati and co-workers studied a solvent-free synthesis of new coumarins characterized by UV-Visible, FTIR and NMR spectroscopic methods with the theoretical estimation of atomic charges, heat of formation, and stereochemistry. ${ }^{17}$ Irfan and co-workers studied the geometries of ground and excited states, excitation energies and UV absorption spectra of a variety of coumarin derivatives. ${ }^{18}$ Similar to the work of Preat et al., their investigation used a time-dependent density functional theory (TD-DFT) approach. ${ }^{19}$ Regulska and co-workers studied alkali metal phenoxyacetates for theoretical- and experimental-data comparisons involving spectroscopic properties. ${ }^{20}$ Costa and co-workers studied the combined experimental and structural, vibrational, and electronic properties theoretical data of glucoalkaloid strictosidine. ${ }^{21}$ In order to sufficiently compare the experimental results with high-level calculations, appropriate computational-approach methods should be investigated until the structures are optimized based on calculated spectroscopic properties.

In our study, five coumarin derivatives, 4-chloromethyl-6-hydroxyl-coumarin, 4-chloromethyl-7-hydroxyl-

coumarin, 4-chloromethyl-6,7-dihydroxyl-coumarin, 4-chloromethyl-7,8-dihydroxyl-coumarin and 4chloromethyl-5,7-dihydroxyl-coumarin were synthesized using several chemical reaction conditions. The UVVisible, FTIR and NMR spectroscopic properties were measured and calculated to compare the experimental and theoretical methods. The DFT M06-2X/6-311+G(2df,2p) basis set was used in this study to calculate the theoretical data. 


\section{Results and Discussion}

Calculated Data. The chemical structures of 4-chloromethyl-6-hydroxyl-coumarin (compound A), 4chloromethyl-7-hydroxyl-coumarin (compound B), 4-chloromethyl-6,7-dihydroxyl-coumarin (compound C), 4chloromethyl-7,8-dihydroxyl-coumarin (compound $\quad$ D) and 4-chloromethyl-5,7-dihydroxyl-coumarin (compound E) are shown in Figure 1. The geometry-optimization data of compounds A, B, C, D and E were calculated using the M06-2X/6-311 + G (2df, 2p) basis set.<smiles>O=c1cc(CCl)c2cc(O)ccc2o1</smiles>

A
$\mathrm{HO}$<smiles>O=c1cc(CCl)c2ccccc2o1</smiles>

B<smiles>O=c1cc(CCl)c2cc(O)c(O)cc2o1</smiles>

C<smiles>O=c1cc(CCl)c2ccc(O)c(O)c2o1</smiles>

D<smiles>O=c1cc(CCl)c2c(O)cc(O)cc2o1</smiles>

E

Figure 1. Chemical structures of coumarin compounds (A, B, C, D and E).

Those data were compared with UV-Vis, FTIR and NMR spectra obtained from the experimental results. Initially, the bond lengths were assigned for the five coumarin structures. We have observed the shortest bond length of $\mathrm{C}-\mathrm{H}$ bonds for all of five coumarin compounds has a value ranging from $0.96-1.09 \AA$. The $\mathrm{C}-\mathrm{C}$ bond length of the polycyclic aromatic rings were found to be in the range of approximately $1.35-1.50 \AA$; the values were almost identical. Moreover, it was found that the longest bond length of all five coumarin compounds observed belonged to the $\mathrm{C}-\mathrm{Cl}$ bond. The $\mathrm{C}-\mathrm{Cl}$ bonds of all compounds $(\mathrm{A}, \mathrm{B}, \mathrm{C}, \mathrm{D}$ and $\mathrm{E})$ were demonstrated to have a distance of approximately $1.80 \AA$ [see Table S1 in Supplementary Materials (SM)]. Comparing the optimized energies of the mono-hydroxyl-substituted coumarin isomers $A$ and $B$, isomer $B$ had a slightly lower energy value than isomer $A$, with an energy difference of $1.94 \mathrm{Kcal} \mathrm{mol}^{-1}$. Among the di-hydroxyl-substituted coumarins (isomers C, D and E), the lowest energy value was found in isomer $C$. The different energy values between isomers $C$ and $D$, and isomers $C$ and $E$, were 3.01 and $0.83 \mathrm{Kcal} \mathrm{mol}^{-1}$, respectively. Moreover, the structures of compounds $A$ and $B$ showed lower energy values compared with the di-hydroxyl-substituted coumarins $(C-E)$ and represented the more stable of the optimized structures (see Table S2 in SM). The atomic Mulliken charges were analyzed from our calculated results. The regions of the aromatic ring occupied by the hydroxyl groups of each compound tended to have greater electron density than the regions of the lactone groups (see Table S3 in SM). The electron-density distributions of all five coumarin derivatives were also generated in detail (see Table S4 in SM). This inductive-effect phenomena could be explained in good agreement with the theoretical assumptions. 
Table 1. Experimental and theoretical maximum-absorption wavelength $\left(\lambda_{\max }\right)$, oscillator strength $(f)$ and excitation energies (E) of coumarin derivatives by TD-DFT method

\begin{tabular}{cccccc}
\hline Compound* & $\begin{array}{c}\text { Exp. } \\
\lambda_{\max } \\
(\mathrm{nm})\end{array}$ & $\begin{array}{c}\text { Calc. } \\
\lambda_{\max } \\
(\mathrm{nm})\end{array}$ & $\mathrm{E}(\mathrm{eV})$ & $f$ & Solvent used \\
\hline A & 352 & 356 & 4.0681 & 0.1272 & Methanol \\
B & 330 & 329 & 4.3984 & 0.3016 & Methanol \\
C & 348 & 350 & 4.1293 & 0.2644 & Methanol \\
D & 331 & 322 & 4.4939 & 0.2327 & Methanol \\
E & 329 & 325 & 4.4505 & 0.3081 & Methanol \\
\hline
\end{tabular}

*Calculated values were multiplied with the scaling factor in comparison with compound $A$

*For coumarin compounds refer to Figure 1

Ultraviolet-visible spectral assignments. As a molecule absorbs energy, an electron is promoted from an occupied molecular orbital (usually a non-bonding $\mathrm{n}$ or bonding $\pi$ orbital) to an unoccupied molecular orbital (an antibonding $\pi^{*}$ or $\sigma^{*}$ orbital) of greater potential energy. In the absorption spectra evaluation studies, each of the five coumarins were compared using experimental and computational approaches. Preat and coworkers also studied the UV absorption spectra of substituted coumarins in which the substitution positions, labeled as 5-Me, 7,8 di-OH and 6,7-OH, showed as 308,334 and $337 \mathrm{~nm}$, respectively. This was investigated using a theoretical method with B3LYP/6-311+G $(2 d, 2 p)$ basis level. ${ }^{19}$ In our case, all five purified coumarin compounds were obtained from the chemical synthesis of mono- and di-hydroxyphenols and ethyl 4chloroacetoacetate. The experimental $\lambda_{\max }$ values of the compounds $A, B, C, D$ and $E$ (in methanol) were found at 352, 330, 348, 331 and $329 \mathrm{~nm}$, respectively. The absorption spectra for all of the coumarin compounds were calculated based on ground-state geometries. The simulated $\lambda_{\max }$ values obtained by the theoretical approach via TD-DFT and M06-2X functionality with 6-311 + G (2df, 2p) as the basis set, presented at 356, 329, 350,322 and $325 \mathrm{~nm}$, respectively (Table 1). The $\lambda_{\max }$ values of both experimental and calculated results indicated great agreement between both data sets. Typically, for substituents with unshared electrons of an aromatic compound, the non-bonding electrons increase the length of the $\pi$-system through resonance, and shift the primary and secondary absorption bands to longer wavelengths. In fact, the presence of the hydroxylgroup substitution at the C- 6 position of compounds $A$ and $C$ showed the higher absorption when compared to each of their similarly-substituted compounds. This may be due to a lone-pair-electron delocalization effect of an auxochrome (hydroxyl group) on the aromatic ring causing a bathochromic shift. The frontier molecular orbital energies of compounds A, B, C, D and E are listed in Table 2; the plot surfaces of the molecular orbitals are shown in Table S4, pp S9-13, in the Supplementary Material. The highest occupied MO (HOMO) energy levels of compounds A, B, C, D and $E$ were $-0.32,-0.32,-0.31,-032$ and $-0.32 \mathrm{eV}$, respectively. The lowest unoccupied MO (LUMO) energy levels were 0.05, 0.06, 0.05, 0.06 and $0.06 \mathrm{eV}$, respectively. This finding was supported by the fact that the higher electron density of the $\mathrm{OH}$ group at $\mathrm{C}-6$ found in compounds $\mathrm{A}$ and $\mathrm{C}$ showed a lower energy level of LUMO $(0.05 \mathrm{eV})$. Thus, it presented a higher absorbance and narrow-energy levels. Conversely, the absence of an $\mathrm{OH}$ group at $\mathrm{C}-6$ of the coumarin compounds $\mathrm{B}, \mathrm{D}$, and $\mathrm{E}$ resulted in a higher energy level of LUMO (0.06 eV). The HOMO-LUMO energy gaps were calculated using HF/3-21g. In addition, our calculations confirmed the lowest excitation energy for compounds $A$ and $C$, compared to their 
di-OH analogues, at 4.0681 and $4.1293 \mathrm{eV}$, respectively. In addition, the oscillator strengths $(f)$ were also predicted as shown in Table 1.

Table 2. Calculated energy levels of HOMO, LUMO and energy gap (eV).

\begin{tabular}{cccccc}
\hline & Compound A & Compound B & Compound C & Compound D & Compound E \\
\hline H - 3 & -0.45 & -0.44 & -0.44 & -0.44 & -0.44 \\
H - 2 & -0.43 & -0.42 & -0.42 & -0.42 & -0.42 \\
H - & -0.36 & -0.36 & -0.36 & -0.33 & -0.35 \\
H & -0.32 & -0.32 & -0.31 & -0.32 & -0.32 \\
L & 0.05 & 0.06 & 0.05 & 0.06 & 0.06 \\
L + & 0.13 & 0.12 & 0.13 & 0.13 & 0.13 \\
L + 2 & 0.14 & 0.14 & 0.14 & 0.15 & 0.15 \\
L + 3 & 0.20 & 0.20 & 0.20 & 0.21 & 0.22 \\
\hline Gap & -0.37 & -0.38 & -0.36 & -0.38 & -0.38 \\
\hline
\end{tabular}

Vibrational-frequency and intensity assignments. The computed frequencies and intensities of all coumarin derivatives were determined theoretically using M06-2X/6-311 + G (2df, 2p) functionality as shown in Table 3 . The differences of the calculated vibrational frequencies of the coumarin compounds were compared with the associated monitored experimental FTIR data. A scaling factor of the calculated FTIR spectrum at 0.9489 (M06$2 \times 6-311++G(d, p))$ was applied to these vibrational frequencies for the DFT. In addition to the bond strength and atomic masses, the vibrational frequency of a bond is also significantly affected by the electronic and steric factors of the surroundings. Considering the vibrational frequencies of $\mathrm{OH}$-stretching, the exact position and shape of this band depends largely on the degree of H-bonding. A medium-to-strong absorption band from 3700 to $3400 \mathrm{~cm}^{-1}$ is a strong indication that the sample is an alcohol or phenol. A sharp peak typically occurring in gaseous or extremely dilute solutions represents unbound or free $\mathrm{OH}$ group(s) while alcohols and phenols in condensed phases are typically strongly hydrogen bonded, causing broadened bands at lower frequencies. Our calculated results predicted $\mathrm{OH}$-stretching frequencies of all five hydroxyl-substituted coumarins at lower frequencies $\left(2964-3030 \mathrm{~cm}^{-1}\right)$ than the actual experimental results $\left(3111-3294 \mathrm{~cm}^{-1}\right)$. The frequency differences are approximately in the range of $150-250 \mathrm{~cm}^{-1}$. The strongest and sharpest band belonging to $\mathrm{C}=\mathrm{O}$ stretching absorption, however, could be calculated to be around $1767-1774 \mathrm{~cm}^{-1}$, which are higher frequencies than our experimental results $\left(1652-1695 \mathrm{~cm}^{-1}\right)$. Our predictions of $\mathrm{OH}$-stretching and $\mathrm{C}=\mathrm{O}$ stretching absorption bands seem not to be accurate when the H-bonding (inter- and intramolecular) resonance effects are involved. The precise predictions of frequencies could be coming from $\mathrm{C}-\mathrm{C}$ stretching, $\mathrm{C}=\mathrm{C}$ stretching and $\mathrm{C}-\mathrm{Cl}$ stretching. 
Table 3. Experimental and theoretical harmonic frequencies $\left(\mathrm{cm}^{-1}\right)$ and intensities $\left(\mathrm{Km} \mathrm{mol}^{-1}\right)$ assignments for coumarin derivatives.

\begin{tabular}{|c|c|c|c|c|c|c|c|c|c|c|c|c|c|c|c|}
\hline \multicolumn{3}{|c|}{ Compound A } & \multicolumn{3}{|c|}{ Compound B } & \multicolumn{3}{|c|}{ Compound C } & \multicolumn{3}{|c|}{ Compound D } & \multicolumn{3}{|c|}{ Compound E } & \multirow[b]{2}{*}{ Assignment } \\
\hline $\begin{array}{l}\text { Exp. } \\
\left(\mathrm{cm}^{-1}\right)\end{array}$ & $\begin{array}{l}\text { Calc. } \\
\left(\mathrm{cm}^{-1}\right)\end{array}$ & Int. & $\begin{array}{l}\text { Exp. } \\
\left(\mathrm{cm}^{-1}\right)\end{array}$ & $\begin{array}{l}\text { Calc. } \\
\left(\mathrm{cm}^{-1}\right)\end{array}$ & Int. & $\begin{array}{l}\text { Exp. } \\
\left(\mathrm{cm}^{-1}\right)\end{array}$ & $\begin{array}{l}\text { Calc. } \\
\left(\mathrm{cm}^{-1}\right)\end{array}$ & Int. & $\begin{array}{l}\text { Exp. } \\
\left(\mathrm{cm}^{-1}\right)\end{array}$ & $\begin{array}{l}\text { Calc. } \\
\left(\mathrm{cm}^{-1}\right)\end{array}$ & Int. & $\begin{array}{l}\text { Exp. } \\
\left(\mathrm{cm}^{-1}\right)\end{array}$ & $\begin{array}{l}\text { Calc. } \\
\left(\mathrm{cm}^{-1}\right)\end{array}$ & Int. & \\
\hline 3229 & 3027 & 4 & 3294 & 3030 & 5 & $\begin{array}{l}3272 \\
3094\end{array}$ & 3022 & 3 & 3170 & 3017 & 5 & $\begin{array}{l}3111 \\
3090\end{array}$ & 2964 & 7 & $\begin{array}{l}\mathrm{O}-\mathrm{H} \text { stretch } \\
=\mathrm{C}-\mathrm{H} \text { stretch }\end{array}$ \\
\hline 2976 & 2952 & 5 & 2942 & 2947 & 5 & $\begin{array}{l}2971 \\
1738\end{array}$ & 2953 & 5 & 1738 & 2953 & 5 & 2969 & & & $\begin{array}{c}-\mathrm{C}-\mathrm{H} \text { stretch } \\
\mathrm{C}=\mathrm{O} \text { stretch ester }\end{array}$ \\
\hline 1665 & 1768 & 794 & 1695 & 1774 & 753 & 1659 & 1767 & 805 & 1665 & 1768 & 748 & 1652 & 1771 & 769 & $\mathrm{C}=\mathrm{O}$ stretch \\
\hline 1579 & 1572 & 102 & 1606 & 1620 & 106 & 1621 & 1566 & 235 & 1610 & 1617 & 153 & 1594 & 1618 & 295 & $\mathrm{C}=\mathrm{C}$ stretch \\
\hline 1437 & 1429 & 213 & $\begin{array}{l}1558 \\
1449\end{array}$ & 1556 & 145 & $\begin{array}{l}1582 \\
1389\end{array}$ & $\begin{array}{l}1505 \\
1433\end{array}$ & $\begin{array}{l}112 \\
183\end{array}$ & $\begin{array}{l}1585 \\
1512\end{array}$ & $\begin{array}{l}1580 \\
1493\end{array}$ & $\begin{array}{l}91 \\
75\end{array}$ & $\begin{array}{l}1459 \\
1369\end{array}$ & 1439 & 120 & $\begin{array}{c}\text { Aromatic ring } \\
\text { stretch }\end{array}$ \\
\hline $\begin{array}{l}1232 \\
1175\end{array}$ & & & $\begin{array}{l}1312 \\
1137\end{array}$ & 1286 & 226 & 1227 & 1292 & 337 & $\begin{array}{l}1311 \\
1038\end{array}$ & 1290 & 202 & $\begin{array}{l}1260 \\
1169\end{array}$ & 1231 & 151 & C-O stretch \\
\hline 861 & 818 & 28 & 818 & 802 & 36 & 865 & 861 & 33 & 851 & 790 & 28 & 827 & 824 & 51 & $\mathrm{C}-\mathrm{Cl}$ stretch \\
\hline
\end{tabular}

*Int. = intensity 
NMR experimental and theoretical results. The structure of an organic compound may be analyzed and identified by NMR spectroscopy that is capable of assigning the carbon skeleton and adjoined hydrogen atoms. The atomic numbering of compounds A, B, C, D and E are assigned as shown in Figure 2. The experimentally observed ${ }^{13} \mathrm{C}$ NMR and ${ }^{1} \mathrm{H}$ NMR chemical shifts of all five coumarin compounds, using DMSO- $\mathrm{d}_{6}$ as solvent and TMS as internal reference, are presented in Table 4. The calculation of chemical shifts was carried out theoretically using M06-2X/6-311+ G (2df, 2p) basis level.

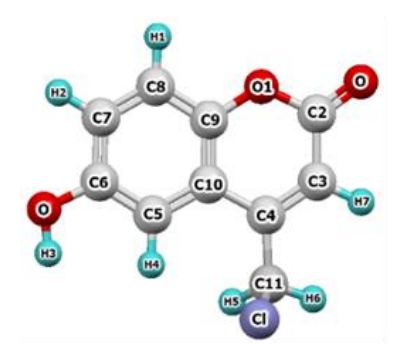

Compound A

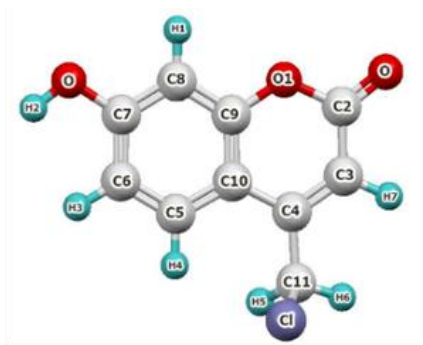

Compound B

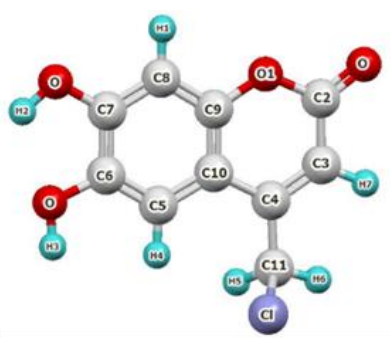

Compound C

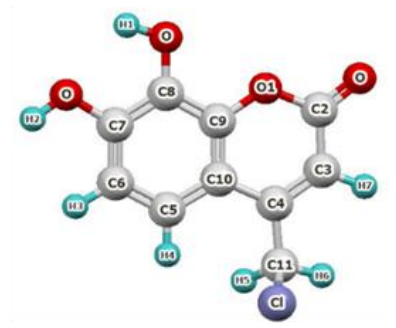

Compound D

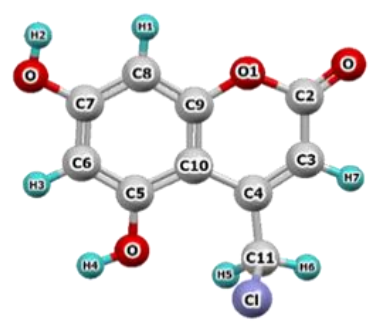

Compound $\mathrm{E}$

Figure 2. The atomic numbering of 4-chloromethyl-6-hydroxyl-coumarin (compound A), 4-chloromethyl-7hydroxyl-coumarin (compound B), 4-chloromethyl-6,7-dihydroxyl-coumarin (compound C), 4-chloromethyl7,8-dihydroxyl-coumarin (compound D) and 4-chloromethyl-5,7-dihydroxyl-coumarin (compound E).

Table 4. Experimental (TMS as internal reference) and theoretical ${ }^{1} \mathrm{H}$ and ${ }^{13} \mathrm{C}$ chemical shifts (ppm), with theoretical calculations utilizing the Gauge-Independent Atomic Orbital (GIAO) method.

\begin{tabular}{ccccccccccc}
\hline & \multicolumn{2}{c}{ compound A } & \multicolumn{2}{c}{ compound B } & \multicolumn{2}{c}{ compound C } & \multicolumn{2}{c}{ compound D } & \multicolumn{2}{c}{ compound E } \\
\cline { 2 - 11 } Atom $^{\text {a }}$ & $\delta_{\text {exp }}$ & $\delta_{\text {cal }}$ & $\delta_{\exp }$ & $\delta_{\text {cal }}$ & $\delta_{\exp }$ & $\delta_{\text {cal }}$ & $\delta_{\exp }$ & $\delta_{\text {cal }}$ & $\delta_{\exp }$ & $\delta_{\text {cal }}$ \\
\hline H1 & 7.30 & 8.04 & 6.74 & 8.59 & 6.79 & 7.69 & 10.18 & 5.35 & 6.27 & 6.81 \\
H2 & 7.09 & 7.91 & 10.66 & 4.64 & 10.39 & 5.96 & 9.38 & 4.37 & 10.42 & 4.55 \\
H3 & 9.85 & 4.37 & 6.83 & 7.20 & 9.46 & 4.35 & 6.81 & 7.22 & 6.21 & 6.54 \\
H4 & 7.15 & 7.73 & 7.66 & 8.59 & 7.13 & 7.76 & 7.14 & 7.95 & 10.89 & 4.89 \\
H5 & 4.98 & 4.63 & 4.94 & 4.73 & 4.91 & 4.62 & 4.90 & 4.70 & 5.02 & 5.32 \\
H6 & 4.98 & 4.27 & 4.94 & 4.22 & 4.91 & 4.26 & 4.90 & 4.30 & 5.02 & 3.96 \\
H7 & 6.66 & 6.92 & 6.41 & 6.75 & 6.41 & 6.77 & 6.38 & 6.77 & 6.23 & 6.56 \\
C2 & 159.9 & 172.2 & 161.5 & 171.9 & 160.5 & 172.8 & 160.1 & 171.7 & 161.5 & 171.7 \\
C3 & 115.6 & 138.6 & 113.2 & 133.0 & 109.4 & 134.2 & 110.1 & 134.4 & 108.8 & 132.3 \\
C4 & 153.8 & 170.9 & 155.4 & 171.6 & 150.7 & 171.4 & 151.4 & 172.6 & 156.5 & 173.6 \\
C5 & 109.6 & 124.1 & 126.6 & 146.6 & 108.9 & 123.2 & 115.5 & 132.9 & 160.1 & 174.4 \\
C6 & 150.3 & 171.2 & 109.4 & 125.7 & 142.9 & 154.6 & 111.0 & 123.3 & 99.2 & 111.0 \\
C7 & 117.6 & 138.9 & 160.3 & 180.7 & 148.3 & 167.7 & 149.8 & 162.3 & 157.2 & 180.2 \\
\hline
\end{tabular}


Table 4. Continued

\begin{tabular}{ccccccccccc}
\hline & \multicolumn{2}{c}{ compound A } & \multicolumn{2}{c}{ compound B } & \multicolumn{2}{c}{ compound C } & \multicolumn{2}{c}{ compound D } & \multicolumn{3}{c}{ compound E } \\
\cline { 2 - 11 } Atom $^{\text {a }}$ & $\delta_{\exp }$ & $\delta_{\text {cal }}$ & $\delta_{\exp }$ & $\delta_{\text {cal }}$ & $\delta_{\exp }$ & $\delta_{\text {cal }}$ & $\delta_{\exp }$ & $\delta_{\text {cal }}$ & $\delta_{\exp }$ & $\delta_{\text {cal }}$ \\
\hline C8 & 117.7 & 138.7 & 102.6 & 119.8 & 102.9 & 121.0 & 132.5 & 150.6 & 94.8 & 109.2 \\
C9 & 146.6 & 167.6 & 151.1 & 177.5 & 150.6 & 170.7 & 143.7 & 161.5 & 152.1 & 179.0 \\
C10 & 120.3 & 134.3 & 111.1 & 126.1 & 111.2 & 125.1 & 112.3 & 128.7 & 99.8 & 114.3 \\
C11 & 41.4 & 47.6 & 41.4 & 47.7 & 41.6 & 48.6 & 41.5 & 47.5 & 45.00 & 51.2 \\
\hline
\end{tabular}

${ }^{a}$ For atomic numbering refer to Figure 2.

For the chemical shifts of the protons attached to the aromatic rings of the coumarin derivatives, the calculated values tended to have slightly higher values (lower field) compared to the experimental values, i.e., approximately 0.4-0.7 ppm. In contrast, the chemical shifts of the protons at C-11 (chloromethyl group) from the calculations were observed at higher fields compared to the observed values. The ${ }^{1} \mathrm{H}$ chemical shifts of the hydroxyl-hydrogens from the experiments appeared at lower fields (9-11 ppm.) while the computed chemical shifts were in the range of 4-6 ppm. This may be due to the effects of intermolecular $\mathrm{H}$-bonding of the coumarin compounds in the media. In the case of the ${ }^{13} \mathrm{C}$ chemical shifts, lower-field shifts were observed at C-2 and C-4 of all five coumarin compounds because of the electron-delocalization (resonance) effect of the electron-withdrawing nature of the carbonyl group. In addition, the lower fields observed for the carbon attached to the hydroxyl group at C5 - C9 were also observed in the range of 140-180 ppm depending on the hydroxyl-substituted positions. The ${ }^{13} \mathrm{C}$ chemical shifts of $\mathrm{C}-11\left(\mathrm{CH}_{2}-\mathrm{Cl}\right)$, both from calculated and experimental results, appear at around $40-50 \mathrm{ppm}$. The calculated ${ }^{1} \mathrm{H}$ and ${ }^{13} \mathrm{C}$ chemical shifts were predicted and in good agreement with the experimental results.

\section{Conclusions}

In this study, the UV-Visible, FTIR and NMR spectra of five substituted chloromethylcoumarin derivatives were compared using experimental and theoretical results. The calculated values of absorption, frequencies and chemical shifts of hydrogen and carbon atoms of substituted-coumarin derivatives were found to be in close agreement with the resulting experimental values. This work provides informative and useful spectroscopicdata comparisons pertaining to intriguing synthetic chemical intermediates such as hydroxyl-substituted-4chloromethylcoumarin derivatives. This detailed data could be applied to the selection criteria of compounds which could be used as intermediates for appropriate chemical modifications and applications. Further investigations related to the chemical properties of these intermediates and other related derivatives, such as amino-substituted-4-chloromethylcoumarins, are in progress.

\section{Experimental Section}

General. Hydroquinone (1,4-dihydroxybenzene), resorcinol (1,3-dihydroxybenzene), 1,2,3-trihydroxybenzene, 1,2,4-trihydroxybenzene, 1,3,5-trihydroxybenzene, ethyl 4-chloroacetoacetate, methane sulfonic acid and DMSO- $d_{6}$ were purchased from Sigma-Aldrich. Sulfuric acid and ethanol were purchased from Carlo Erba. Other reagents were directly used as obtained commercially. Coumarin compounds A, B, C, D and E were 
synthesized in our laboratory; all of the desired products were obtained as purified solids. All synthesized compounds were characterized and recorded by spectroscopic techniques. UV-Visible absorption spectra were recorded on an Agilent Cary Series UV-VIS-NIR spectrophotometer. FTIR spectra of the coumarin compounds were recorded on a Thermo Scientific ${ }^{\mathrm{TM}}$ model Nicolet 6700 spectrometer in ATR mode within the region of $4000-400 \mathrm{~cm}^{-1}$. Only significant absorptions are listed. ${ }^{1} \mathrm{H} N \mathrm{NM}$ and ${ }^{13} \mathrm{C} \mathrm{NMR}$ spectra of the coumarin compounds in deuterated dimethyl sulfoxide (DMSO- $d_{6}$ ) solution were recorded on a Bruker AVANCE HD 500 $\mathrm{MHz}\left({ }^{1} \mathrm{H}: 500 \mathrm{MHz},{ }^{13} \mathrm{C}: 125 \mathrm{MHz}\right)$ using tetramethylsilane (TMS) as an internal reference. The chemical shifts $(\delta)$ and coupling constants $(\mathrm{J})$ are expressed in ppm and $\mathrm{Hz}$, respectively. Melting points were uncorrected and determined on a Büchi Melting Point B-545 apparatus. High-resolution mass spectroscopy was performed on a Bruker Daltonics spectrometer model MicrOTOF (ESI+mode) and reported with ion mass/charge $(\mathrm{m} / \mathrm{z}) \mathrm{ratios}$ as values in atomic mass units.

4-Chloromethyl-6-hydroxyl-coumarin (compound A). To a round-bottom flask, hydroquinone (5.5 g, 50 $\mathrm{mmoL})$ and methane sulfonic acid $(75 \mathrm{~mL})$ were mixed and then ethyl-4-chloroacetoacetate $(8.2 \mathrm{~g}, 6.3 \mathrm{~mL}, 50$ $\mathrm{mmoL}$ ) was added dropwisely. The resulting solution was allowed to stir at room temperature for $12 \mathrm{~h}$. Then iced water $(400 \mathrm{~mL})$ was added and stirred for an additional $6 \mathrm{~h}$. The suspension was filtered and washed with cold water several times. The obtained solid was recrystallized in ethanol and dried under vacuum overnight to give compound $\mathbf{A}$ as a white solid (6.9 g, 65\%). mp 222-223 ${ }^{\circ} \mathrm{C}$; FTIR (ATR, $\left.\mathrm{v}_{\max }, \mathrm{cm}^{-1}\right): 3229$ (O-H), 2976, 2941 (-C-H) 1665 (lactone C=O), 1579 (C=C), 1437 (aromatic ring), 1232, 1175 (C-O), $861(\mathrm{C}-\mathrm{Cl}) ;{ }^{1} \mathrm{H} \mathrm{NMR}(500$ $\left.\mathrm{MHz}, \mathrm{DMSO}-d_{6}\right): \delta_{\mathrm{H}} 4.98\left(2 \mathrm{H}, \mathrm{s}, \mathrm{CH}_{2} \mathrm{Cl}\right), 6.66(1 \mathrm{H}, \mathrm{s},=\mathrm{CHC}=0), 7.09(1 \mathrm{H}, \mathrm{dd}, J$ 8.9, $2.7 \mathrm{~Hz}, \mathrm{C} 7-\mathrm{H}$ aromatic), 7.15 $\left(1 \mathrm{H}, \mathrm{d}, J 2.7 \mathrm{~Hz}, \mathrm{C} 5-\mathrm{H}\right.$ aromatic), $7.30\left(1 \mathrm{H}, \mathrm{d}, J 8.9 \mathrm{~Hz}, \mathrm{C} 8-\mathrm{H}\right.$ aromatic), $9.85(1 \mathrm{H}, \mathrm{br} \mathrm{s}, \mathrm{C} 6-\mathrm{OH}) ;{ }^{13} \mathrm{C} \mathrm{NMR}(125$ $\left.\mathrm{MHz}, \mathrm{DMSO}-d_{6}\right): \delta_{c} 41.4,109.6,115.6,117.6,117.7,120.3,146.6,150.3,153.8,159.9 ;$ UV-Vis $\lambda_{\max }{ }^{\mathrm{HEPES} / \mathrm{MeOH}}$ ${ }^{(20 / 80)}\left(\varepsilon \mathrm{M}^{-1} \mathrm{~cm}^{-1}\right) 226\left(1.33 \times 10^{4}\right), 278\left(0.62 \times 10^{4}\right), 352\left(0.25 \times 10^{4}\right) \mathrm{nm} ; \mathrm{HMRS}(\mathrm{ESI}): \mathrm{m} / z$ calcd. for $\mathrm{C}_{10} \mathrm{H}_{8} \mathrm{ClO}_{3}$ $[\mathrm{M}+\mathrm{H}]^{+}, 211.0162 ;$ found, 211.0153 .

4-Chloromethyl-7-hydroxyl-coumarin (compound B). Resorcinol (5.29 g, $48 \mathrm{mmol}$ ) and ethyl-4chloroacetoacetate $(6.58 \mathrm{~g}, 5.4 \mathrm{ml}, 40 \mathrm{mmol})$ were added to conc. $\mathrm{H}_{2} \mathrm{SO}_{4}(40 \mathrm{~mL})$ and stirred at $0{ }^{\circ} \mathrm{C}$ for $2 \mathrm{~h}$. Then ice and water $(100 \mathrm{~mL})$ were added, the suspension was filtered and washed with cold water. The obtained solid was recrystallized in ethanol and dried under vacuum overnight to give compound $\mathbf{B}$ as a white solid (5.81 g, 69\%). mp 181-183 ${ }^{\circ} \mathrm{C} ;{ }^{23}$ FTIR (ATR, vmax, cm-1): $3294(\mathrm{OH}), 2942(-\mathrm{C}-\mathrm{H}) 1695$ (lactone C=O), 1606 $(\mathrm{C}=\mathrm{C}), 1558,1449$ (aromatic ring), 1312 (C-O), 1137 (C-O), $818(\mathrm{C}-\mathrm{Cl}) ;{ }^{1} \mathrm{H}$ NMR $\left(500 \mathrm{MHz}, \mathrm{DMSO}-d_{6}\right): \delta_{\mathrm{H}} 4.94$ $\left(2 \mathrm{H}, \mathrm{s}, \mathrm{CH}_{2} \mathrm{Cl}\right), 6.41(1 \mathrm{H}, \mathrm{s},=\mathrm{CHC}=\mathrm{O}), 6.74(1 \mathrm{H}, \mathrm{d}, J 2.0 \mathrm{~Hz}, \mathrm{C} 8-\mathrm{H}$ aromatic $), 6.83(1 \mathrm{H}, \mathrm{dd}, J 8.8,2.0 \mathrm{~Hz}, \mathrm{C} 6-\mathrm{H}$ aromatic), $7.66\left(1 \mathrm{H}, \mathrm{d}, J 8.8 \mathrm{~Hz}, \mathrm{C} 5-\mathrm{H}\right.$ aromatic), $10.66\left(1 \mathrm{H}\right.$, br s, C7-OH); ${ }^{13} \mathrm{C} \mathrm{NMR}\left(125 \mathrm{MHz}, \mathrm{DMSO}-d_{6}\right): \delta_{\mathrm{C}}$ 41.4, 102.6, 109.4, 111.1, 113.2, 126.6, 151.1, 155.4, 160.3, 161.5; UV-Vis $\lambda_{\max }{ }^{\mathrm{HEPES} / \mathrm{MeOH}(20 / 80)}\left(\varepsilon \mathrm{M}^{-1} \mathrm{~cm}^{-1}\right) 217$ $\left(1.19 \times 10^{4}\right), 330\left(0.99 \times 10^{4}\right) \mathrm{nm}$; HMRS $(\mathrm{ESI}): \mathrm{m} / z$ calcd. for $\mathrm{C}_{10} \mathrm{H}_{8} \mathrm{ClO}_{3}[\mathrm{M}+\mathrm{H}]^{+}, 211.0162$; found, 211.0164 .

4-Chloromethyl-6,7-dihydroxyl-coumarin (compound C). 1,2,3-trihydroxybenzene (6.31 g, $50 \mathrm{mmoL}$ ) was dissolved in conc. $\mathrm{H}_{2} \mathrm{SO}_{4}(2 \mathrm{~mL})$ and ethyl 4-chloroacetoacetate $(8.23 \mathrm{~g}, 6.76 \mathrm{~mL}, 50 \mathrm{mmoL})$ was added to the solution. The reaction mixture was stirred at $0{ }^{\circ} \mathrm{C}$ for $1 \mathrm{~h}$. Then ice and water $(100 \mathrm{~mL})$ were added, the suspension was filtered and washed with cold water. The obtained solid was recrystallized in ethanol and dried under vacuum overnight to give compound $\mathbf{C}$ as a yellow solid $(6.91 \mathrm{~g}, 61 \%) . \mathrm{mp} 265-266^{\circ} \mathrm{C}$; FTIR (ATR, $\left.V_{\max } \mathrm{cm}^{-1}\right): 3272(\mathrm{OH}), 3094(=\mathrm{C}-\mathrm{H}), 2971(-\mathrm{C}-\mathrm{H}), 1738(\mathrm{C}=\mathrm{O}), 1659$ (lactone $\left.\mathrm{C}=\mathrm{O}\right), 1621(\mathrm{C}=\mathrm{C}), 1582,1389$ (aromatic ring), $1227(\mathrm{C}-\mathrm{O}), 865(\mathrm{C}-\mathrm{Cl}) ;{ }^{1} \mathrm{H}$ NMR $\left(500 \mathrm{MHz}, \mathrm{DMSO}-d_{6}\right): \delta_{\mathrm{H}} 4.91\left(2 \mathrm{H}, \mathrm{s}, \mathrm{CH}_{2} \mathrm{Cl}\right), 6.41(1 \mathrm{H}, \mathrm{s}$, $=\mathrm{CHC}=0), 6.79(1 \mathrm{H}, \mathrm{s}, \mathrm{C} 8-\mathrm{H}$ aromatic), $7.13(1 \mathrm{H}, \mathrm{s}, \mathrm{C} 5-\mathrm{H}$ aromatic), $9.46(1 \mathrm{H}, \mathrm{br} \mathrm{s}, \mathrm{C} 6-\mathrm{OH}), 10.39$ (1H, br s, C7$\mathrm{OH}) ;{ }^{13} \mathrm{C} N M R\left(125 \mathrm{MHz}\right.$, DMSO- $\left.d_{6}\right): \delta_{c} 41.6,102.9,108.9,109.4,111.2,142.9,148.3,150.6,150.7$, 160.5; UV- 
Vis $\lambda_{\max }{ }^{\text {HEPES} / \mathrm{MeOH}(20 / 80)}\left(\varepsilon \mathrm{M}^{-1} \mathrm{~cm}^{-1}\right) 215\left(1.63 \times 10^{4}\right), 348\left(1.11 \times 10^{4}\right) \mathrm{nm} ; \mathrm{HMRS}(\mathrm{ESI}): \mathrm{m} / z$ calcd. for $\mathrm{C}_{10} \mathrm{H}_{8} \mathrm{ClO}_{4}$ $[\mathrm{M}+\mathrm{H}]^{+}, 227.0111$; found, 227.0100 .

4-Chloromethyl-7,8-dihydroxyl-coumarin (compound D). 1,2,4-trihydroxybenzene (0.5 g, $3.96 \mathrm{mmoL}$ ) was dissolved in conc. $\mathrm{H}_{2} \mathrm{SO}_{4}(1 \mathrm{~mL})$ and ethyl 4-chloroacetoacetate $(0.65 \mathrm{~g}, 0.54 \mathrm{~mL}, 3.96 \mathrm{mmoL})$ was added to the solution. The reaction mixture was stirred at $0{ }^{\circ} \mathrm{C}$ for $2 \mathrm{~h}$. Then ice and water $(50 \mathrm{~mL})$ were added, the suspension was filtered and washed with cold water. The obtained solid was recrystallized in ethanol and dried under vacuum overnight to give compound $D$ as a pale yellow solid $(0.74 \mathrm{~g}, 82 \%)$. mp $198-200{ }^{\circ} \mathrm{C} ;{ }^{23} \mathrm{FTIR}$ $\left(A T R, v_{\max } \mathrm{cm}^{-1}\right): 3170(\mathrm{OH}), 1738(\mathrm{C}=\mathrm{O}), 1665$ (lactone $\left.\mathrm{C}=\mathrm{O}\right), 1610(\mathrm{C}=\mathrm{C}), 1585,1512$ (aromatic ring), 1311, $1038(\mathrm{C}-\mathrm{O}), 851(\mathrm{C}-\mathrm{Cl}) ;{ }^{1} \mathrm{H}$ NMR $\left(500 \mathrm{MHz}, \mathrm{DMSO}-d_{6}\right): \delta_{\mathrm{H}} 4.90\left(2 \mathrm{H}, \mathrm{s}, \mathrm{CH}_{2} \mathrm{Cl}\right), 6.38(1 \mathrm{H}, \mathrm{s},=\mathrm{CHC}=\mathrm{O}), 6.81(1 \mathrm{H}, \mathrm{d}$, J $8.7 \mathrm{~Hz}, \mathrm{C} 6-\mathrm{H}$ aromatic), $7.14(1 \mathrm{H}, \mathrm{d}, J 8.7 \mathrm{~Hz}, \mathrm{C} 5-\mathrm{H}$ aromatic), $9.38(1 \mathrm{H}, \mathrm{br} \mathrm{s}, \mathrm{C} 7-\mathrm{OH}), 10.18(1 \mathrm{H}, \mathrm{br} \mathrm{s}, \mathrm{C} 8-\mathrm{OH})$; ${ }^{13} \mathrm{C}$ NMR $\left(125 \mathrm{MHz}\right.$, DMSO- $\left.d_{6}\right): \delta_{c} 41.5,110.1,111.0,112.3,115.5,132.5,143.7,149.8,151.4,160.1 ;$ UV-Vis $\lambda_{\max }{ }^{\text {HEPES} / \mathrm{MeOH}}(20 / 80)\left(\varepsilon \mathrm{M}^{-1} \mathrm{~cm}^{-1}\right) 217\left(1.91 \times 10^{4}\right), 331\left(0.76 \times 10^{4}\right) \mathrm{nm} ; \mathrm{HMRS}(\mathrm{ESI}): \mathrm{m} / z$ calcd. for $\mathrm{C}_{10} \mathrm{H}_{8} \mathrm{ClO}_{4}$ $[\mathrm{M}+\mathrm{H}]^{+}, 227.0111$; found, 227.0106 .

4-Chloromethyl-5,7-dihydroxyl-coumarin (compound E). To round-bottom flask, 1,3,5-trihydroxybenzene (6.3 $\mathrm{g}, 50 \mathrm{mmoL})$ and methane sulfonic acid $(75 \mathrm{~mL})$ were mixed and then ethyl 4-chloroacetoacetate $(8.2 \mathrm{~g}, 6.3$ $\mathrm{mL}, 50 \mathrm{mmoL}$ ) was added dropwisely. The resulting solution was allowed to stir at room temperature for $6 \mathrm{~h}$. Then iced water $(400 \mathrm{~mL})$ was added and stirred for additional $6 \mathrm{~h}$. The suspension was filtered and washed with cold water several times. The obtained solid was recrystallized in ethanol and dried under vacuum overnight to give compound $\mathbf{E}$ as a white solid (11.6 g, 99\%). mp 245-246 ${ }^{\circ} \mathrm{C} ;{ }^{23} \mathrm{FTIR}$ (ATR, $\mathrm{V}_{\max }, \mathrm{cm}^{-1}$ ): 3111 $(\mathrm{OH}), 3090(=\mathrm{C}-\mathrm{H}), 2969(-\mathrm{C}-\mathrm{H}), 1652$ (lactone $\mathrm{C}=\mathrm{O}), 1594(\mathrm{C}=\mathrm{C}), 1459,1369$ (aromatic ring), 1260, 1169 (C-O), $827(\mathrm{C}-\mathrm{Cl}) ;{ }^{1} \mathrm{H}$ NMR $\left(500 \mathrm{MHz}, \mathrm{DMSO}-d_{6}\right): \delta_{\mathrm{H}} 5.02\left(2 \mathrm{H}, \mathrm{s}, \mathrm{CH}_{2} \mathrm{Cl}\right), 6.23(1 \mathrm{H}, \mathrm{s},=\mathrm{CHC}=0), 6.21(1 \mathrm{H}, \mathrm{d}, \mathrm{J} 2.3$ $\mathrm{Hz}, \mathrm{C} 6-\mathrm{H}$ aromatic), $6.27\left(1 \mathrm{H}, \mathrm{d}, J 2.3 \mathrm{~Hz}, \mathrm{C} 8-\mathrm{H}\right.$ aromatic), $10.42(1 \mathrm{H}, \mathrm{br} \mathrm{s}, \mathrm{C} 7-\mathrm{OH}), 10.89(1 \mathrm{H}, \mathrm{s}, \mathrm{C} 5-\mathrm{OH}) ;{ }^{13} \mathrm{C}$ NMR (125 MHz, DMSO- $\left.d_{6}\right): \delta_{c} 45.0,94.8,99.2,99.8,108.8,152.1,156.5,157.2,160.1,161.5$; UV-Vis $\lambda_{\max }{ }^{\text {HEPES} / M e O H}(20 / 80)\left(\varepsilon \mathrm{M}^{-1} \mathrm{~cm}^{-1}\right) 217\left(1.55 \times 10^{4}\right), 329\left(1.05 \times 10^{4}\right) \mathrm{nm} ; \mathrm{HMRS}(\mathrm{ESI}): \mathrm{m} / z$ calcd. for $\mathrm{C}_{10} \mathrm{H}_{8} \mathrm{ClO}_{4}$ $[\mathrm{M}+\mathrm{H}]^{+}, 227.0111$; found, 227.0101 .

Computational Details. Initially, the 4-chloromethyl-6-hydroxyl-coumarin, 4-chloromethyl-7-hydroxylcoumarin, 4-chloromethyl-6,7-dihydroxyl-coumarin, 4-chloromethyl-7,8-dihydroxyl-coumarin and 4chloromethyl-5,7-dihydroxyl-coumarin were generated and optimized with a Gaussian 09 program. All optimized structures were carefully checked to be the most stable structure at the optimized local structure. Density functional theory (DFT) using the M06-2X functional approach was applied for this calculation. This method was successfully applied to study the coumarin synthesis in the previous report. ${ }^{23}$ The basis set used was $6-311+G(2 d f, 2 p)$. The time-dependent density functional theory (TD-DFT) and molecular orbital theory were used to predict the adsorption-spectroscopy wavelengths. The ${ }^{13} \mathrm{C}-\mathrm{NMR}$ and ${ }^{1} \mathrm{H}-\mathrm{NMR}$ chemical shifts, harmonic vibrational-frequency spectra, and molecular orbitals of the excited states were calculated based on their optimized geometries using the Gauge-Independent Atomic Orbital (GIAO) method.

\section{Acknowledgements}

This work has been supported in part by grants from Graduate School Kasetsart University and Department of Chemistry, Faculty of Liberal Arts and Science, Kasetsart University (Kamphaengsaen Campus). 


\section{Supplementary Material}

Calculated geometrical parameters for bond-length distances, $\mathrm{M06}-2 \mathrm{X} / 6-311+\mathrm{G}(2 \mathrm{df}, 2 \mathrm{p})$, calculated charge and calculated energy levels of HOMO, LUMO and energy gap (eV) (Tables S1, S2, S3, and S4) and experimental UV-Visible, FTIR, ${ }^{1} \mathrm{H}-\mathrm{NMR}$ and ${ }^{13} \mathrm{C}-\mathrm{NMR}$ spectra, and high-resolution mass spectra (Figures S1, S2, S3 and S4) of five 4-chloromethylcoumarin compounds $(A, B, C, D$ and $E)$ can be found in the supplementary material file.

\section{References}

1. Penta, S. Advances in Structure and Activity Relationship of Coumarin Derivatives. Academic Press: Oxford, 2016; p1.

https://doi.org/10.1016/B978-0-12-803797-3.00001-1

2. Stamboliyska, B.; Janevska, V.; Shivachev, B.; Nikolova, R. P.; Stojkovic, G.; Mikhova, B.; Popovski, E. ARKIVOC 2010, 10, 62.

http://dx.doi.org/10.3998/ark.5550190.0011.a06

3. Srikrishna, D.; Godugu, C.; Dubey, P. K. Mini-Rev. Med. Chem. 2016, 18, 1.

https://doi.org/10.2174/1389557516666160801094919

4. Poumale, H. M. P.; Hamm, R.; Zang, Y.; Shiono, Y.; Kuete, V. Medicinal Plant Research in Africa:

Pharmacology and Chemistry, Elsevier: Oxford, 2013; p 261.

http://dx.doi.org/10.1016/B978-0-12-405927-6.00008-4

5. Vekariya, R. H.; Patel, H. D. Synthetic Commun. 2014, 44, 2756.

https://doi.org/10.1080/00397911.2014.926374

6. Subramaniam, R.; Xiao, Y.; Li, Y.; Qian, S. Y.; Sun, W.; Mallik, S. Tetrahedron Lett. 2010, 51, 529. https://doi.org/10.1016/j.tetlet.2009.11.084

7. Atta, S.; Ikbal, M.; Kumar, A.; Singh, N. D. P. J. Photoch. Photobio. B 2012, 111, 39. https://doi.org/10.1016/i.jphotobiol.2012.03.008

8. Kah, M.; Beulke, S.; Tiede, K.; Hofmann, T. Crit. Rev. Env. Sci. Tec. 2013, 43, 1823. https://doi.org/10.1080/10643389.2012.671750

9. Lin, Q.; Bao, C.; Fan, G.; Cheng, S.; Liu, H.; Liu, Z.; Zhu, L. J. Mater. Chem. 2012, 22, 6680. https://doi.org/10.1039/c2jm30357d

10. Atta, S.; Jana, A.; Ananthakirshnan, R.; Dhuleep, P. S. N. J. Agri. Food Chem. 2010, 58, 11844. https://doi.org/10.1021/jf1027763

11. Sombat, W.; Wongkhan, K.; Jarussophon, S.; Jitchati, R. Defect Diffus. Forum 2017, 381, 26. https://doi.org/10.4028/www.scientific.net/ddf.381.26

12. Zhang, Y.; Ren, P.; Li, Y.; Su, R.; Zhao, M. J. Chem.-NY. 2015, 1. https://doi.org/10.1155/2015/402746

13. Prashanth, J.; Ojha, J. K.; Reddy, B. V.; Rao, G. R. J. Phys. Conf. Ser. 2016, 759, 012057 https://doi.org/10.1088/1742-6596/759/1/012057

14. Sundaraganesan, N.; Ilakiamani, S.; Anand, B.; Saleem, H.; Joshua, B. D. Spectrochim. Acta A 2006, 64, 586. https://doi.org/10.1016/i.saa.2005.07.061 
15. Sundaraganesan, N.; Saleem, H.; Mohan, S.; Ramalingam, M.; Sethuraman, V. Spectrochim. Acta A 2005, $62,740$.

https://doi.org/10.1016/i.saa.2005.02.043

16. Ghogomu, J. N.; Nkungli, N. K. Adv. Chem. 2016, 1.

https://doi.org/10.1155/2016/9683630

17. Al-Bayati, R. I.; Radey, M. F.; Al-Amiery, A. A. Org. Chem. Inter. 2012, 1. https://doi.org/10.1155/2012/828032

18. Irfan, M.; Iqbal, J.; Eliasson, B.; Ayub, K.; Rana, U. A.; Ud-Din Khan, S. J. Mol. Struct. 2017, 1130, 603. https://doi.org/10.1016/i.molstruc.2016.11.026

19. Preat, J.; Jacquemin, D.; Perpète, E. A. Chem. Phys. Lett. 2005, 415, 20. https://doi.org/10.1016/j.cplett.2005.08.135

20. Regulska, E.; Samsonowicz, M.; Świsłocka, R.; Lewandowski, W. Adv. Biomed. Spec. 2013, 7, 227. https://doi.org/10.3233/978-1-61499-184-7-227

21. Costa, R. A.; Pinheiro, M. L. B.; de Oliveira, K. M. T.; Barison, A.; Salomé, K. S.; lank, J. R.; da Silva, N. G.; Cabral, T. S.; Costa, E. V. J. Chem.-NY. 2016, 1. https://doi.org/10.1155/2016/1752429

22. Ye, X.-W.; Zheng, Y.-C.; Duan, Y.-C.; Wang, M.-M.; Yu, B.; Ren, J.-L.; Ma, J.-L.; Zhang, E.; Liu, H.-M. Med. Chem. Commun. 2014, 5, 650. http://doi.org/10.1039/c4md00031e

23. Pornsatitworakul, S.; Boekfa, B.; Maihom, T.; Treesukol, P.; Namuangruk, S.; Jarussophon, S.; Jarussophon, N.; Limtrakul, J. Monatsh. Chem. 2017, 148, 1245.

https://doi.org/10.1007/s00706-017-1962-4 